\title{
Pedagogical Experience of Classroom Teachers in English as a Medium of Instruction
}

\author{
Suresh Kumar Shrestha \\ Tribhuvan University, Nepal \\ sureshkrshrestha@gmail.com
}

\section{Abstract}

English as a medium of instruction (EMI), especially at public schools, is a matter of curiosity and exploration among Nepalese academicians and researchers, as it is already in policy and practice with the growing number of public schools implementing it. Therefore, it is essential to explore the perceptions and experiences of all the stakeholders in Nepal to address the issues of EMI in the local context. The article outlines teachers' experiences of EMI in classes in the Nepalese multilingual context. It builds upon the experiences of three teachers teaching several subjects including English at private and public EMI schools. The semi-structured written interviews were employed to collect required data. The teachers' experiences have been presented in four aspects: teaching techniques, achievements, challenges and strategies disclose the hopes and challenges both the teachers and students including parents and school administration experience. The findings hint the imperativeness of discussions at different levels from locals to policy makers for the proper undestaning and management of EMI at schools.

Keywords: EMI practice, multilingualism, teachers' experiences, teacher techniques

\section{Introduction}

Is English the most reliable language of seven C's - charm, chance, challenge, collaboration, command, career and contentment or anything else? It is clear to all the people who are aware of the importance of English that it has left deep impression on all those who are able or unable to speak it. The growing popularity and prosperity of English along with its use as a lingua franca, international language and global language leaves no space for cynicism that it is broadly used as a basis of success and survival in diverse fields across the globe. That is what it is reflected by remarks made by Byun, Chu, Kim, Park, Kim, and Jung (2011, p. 432):

Given today's degree of globalization and the dominance of English as a global lingua franca, a working knowledge of spoken and written English is increasingly 
perceived as an indispensable competency in various fields, including business, diplomacy, and-more and more-academia.

Even today's nonprofessionals sound convinced that those who have English proficiency can grab chances to have a great designation no matter where they are; and, those who can at least speak fluent English can survive successfully with a satisfactory career. Tourist guides in tourism centers and busy employees at call centers are some of the examples of the power of the prestigious language. It is the charm of English that the non-native speakers of English in the world have already outnumbered the speakers of English as a first or a second language. Sah $(2015$, p. 1) also asserts the influence of English as:

The rise of English as a global lingua franca seems to be further forcing non-native speakers to learn English and many countries are trying to drastically overhaul their education system in favour of English in order to meet the challenge of global integration.

Such a global perception and practice of English has not left Nepal and Nepalese pedagogy unaffected. Besides Nepali, many more government and community schools in Nepal have adopted English as a medium of instruction (EMI). With some hope for and curiosity about EMI, Dearden (2014, p. 4) states:

$\mathrm{EMI}$ is increasingly being used in universities, secondary schools and even primary schools. This phenomenon has very important implications for the education of young people. Yet little empirical research has been conducted into why and when EMI is being introduced and how it is delivered.

Nevertheless, pactising EMI in education system needs to be based on researches and their findings. In today's globalized world, no classes are found to be homogeneous. Therefore, it is really challenging to have monolingual medium of instruction, no matter whether it is English or something else. It matters a lot when it comes to the autonomous learning of students. Hence the effectiveness of EMI needs weighing against teaching learning outcomes as stressed by Ibrahim, Anka, and Yabo (2017, p. 64):

In any teaching and learning situation the language of instruction plays a very vital role in facilitating learning of subject contents. So, it is necessary for the teachers and learners to use the language of instruction appropriately for enhancing effective teaching and learning. 
In the case of Nepal almost all the classes are heterogeneous in terms of age, intelligence, culture, language, society, etc. When it comes to mother tongue or first language, the heterogeneous classes are said to be multilingual. Moreover, as stated by Ghimire (2011), Nepal has been a country of multilingualism since the pre-modern era, and people living in various ethnic groups speak different languages (Tobin, 2011). No doubt, the teachers teaching in such classes have their own experiences of facing challenges with certain strategies, as the popularity of EMI is growing constantly not only among schools but also among students and parents. Therefore, it is interesting to explore their perception and practice of teaching in multilingual classes in the English medium.

\section{Research Questions}

- What pedagogical experience do teachers of EMI have in multilingual classes?

- How do they perceive multilingual practice in the classes with EMI?

\section{Literature Review}

The emergence of English as a global language is the index of its essentiality in all the fields for each and every kind of job whether it is for the post of a doorman at a five-star hotel or a counsellor at a consultancy of a diplomat in some department. The availability of various means of communication in global network and chunks of information on the internet especially in English establish the poweful role of English as a tool to facilitate worldwide exchange of information for the development of knowledge as well as career enhancement and mobility (Montgomery, 2004). The prevalence of English in the documentation of official records and transactions in government organizations and departments has offered English in the status of second language although it has not been formally declared. And, EMI in Nepalese pedagogcial practice is also seen as the requirement of English, whereas it is also viewed as a competition with private schools weighing the students and parents' faith in the influence of English on their career.

To be clear about EMI, there are several suggestions and definitions shared by scholars and researchers. Cosgun and Hasirci (2017) perceive EMI as the use of English in all the pedagogical aspects, such as course content, lessons, assignments, etc. And, Dearden (2014, p. 4) asserts the notion of EMI to "the use of English language to teach academic subjects in countries or jurisdictions where the first language (L1) of the majority of the population is not English." 
Cosgun and Hasirci (2017) express the growing EMI attraction in Nepal just as more and more non-English speaking countries in the world are getting attracted to implement EMI for higher education, giving the example of EMI status in Turkey.

Likewise, underscoring the rise of EMI in Asian countries as agreed to by Naun (2003), Hu (2009, p. 47) presents how EMI is gaining popularity in China as:

Although the organised promotion of English medium instruction in contemporary China started only at the turn of this century, the use of English as a medium of instruction in China's educational institutions has gathered great momentum in the last few years and is now sweeping across the educational landscape.

Nepalese scholars' views on EMI in the context of Nepal reflect school administrators', teachers', parents' and students' faith in it. Aryal (2013) hints the parental discourse that their children's better career is closely tied to better English and it is EMI that ensures it. Prioritizing the prospective employees with English efficiency at NGOs, INGOs and other multinational companies and the indispensibility of English for abroad education as a hallmark of quality are the reasons for parents' inclination to EMI. In this regard, Phyak, (2011) is a bit critical and conscious about subtle importance of multilingual education rather than or as well as switching to EMI just for the justification of 'quality education' at public schools like that as private ones. So, it is the case of quality in education with education in English in parents' thinking and understandig without any in-depth reseach and findings the nexus between quality education and EMI. The remark made by Ojha (2018, p. 196) shows his skepticism about only EMI for quality education and suggests quality teaching for that:

Introducing EMI is not a solution to overcoming the long-standing problem of degradation of quality education in community schools[...] it is suggested that government community schools should focus on teaching effectively in their students' mother tongue rather than teaching in English; and the medium should not be changed solely as a survival technique to compete with private schools.

Awareness of Asian countries' preference to EMI for human capital development, Doiz, Lasagabaster, \& Sierra (2012, as cited in Sah and Li, 2018) suggest infrasturctural develpment and soundness for countries to achieve their goal, clearly indicating the minimum English skills that the teachers and students need to have for successful implementation of EMI policy. 


\section{Methods}

I employed case study research design in qualitative research approach. I collected data by interviewing three teachers teaching multilingual students at English medium schools in Province Number 2 and 3. One of the teachers is teaching English at a public English medium school. The second teacher is teaching Social Studies and English at the secondary level in a government English medium School. The third one is teaching English at the higher secondary level at a private EMI school. For that purpose, a set of questionnaire was prepared and administered. The teachers shared their experiences of pedagogical practice at EMI schools by providing with the written interviews for analysis.

\section{Data Analysis and Presentation}

I have presented the data collected from the teachers in four steps: 'teaching techniques', 'achievements', 'challenges' and 'strategies'. Besides that, I codified the teachers teaching English at the secondary level, teaching Social Studies and English at the secondary level, and teaching English at the higher secondary level as Teacher A, Teacher B and Teacher $\mathrm{C}$ respectively.

\section{Teacher A}

Teacher A teaches English at the secondary level at a public EMI school, where most of the children have Bhojpuri, Nepali and Maithali as their first language. However, they mostly prefer Nepali to English for communication to comprehend the course materials available in English. She does not need to be able to communicate in all their first languages. The languages she finds feasible in the classes are English and Nepali.

Teaching techniques. The teaching techniques that she employs in the classes are based on how she can make students able to comprehend the teaching contents as they need to be able to learn them from examination view-point. However, she frequently reads out the teaching contents in English, as they are available in English. She explains them to students in English with writing on the board. Sometimes, she translates and explains the contents in Nepali. Students also read the contents in English, but also use Nepali to raise questions or make explanation, beginning in English, as the teacher encourages them to use English. In rare cases, Students use Bhojpuri to communicate with her. However, students most frequently use their first language while having an intra-cultural communication with each other, whereas they use Nepali when they have to have an intercultural communication. 
Achievements. Having a multilingual approach in the EMI classes might not feel to be in favour of English, which has been introduced as a medium of instruction at the school. Nevertheless, the teacher is able to make detailed interpretations with various examples, rather than being limited to a few words in English. Employing multilingual pedagogy, she is able to facilitate students to comprehend the subject matters. They are at least able to explain in their own language what they learn in the classroom.

Challenges. EMI is of course good for students to get English environment at least while communicating with the teacher of English in the school. Nevertheless, she finds EMI a huge challenge in the context she has to teach. In the lack of English environment outside the school, students are deprived of constant exposure to English, since almost all speak in the languages other than in English outside the school. At the same time she takes up the challenges to hone up her own skills and ability to provide with a favorable environment to students.

Strategies. The teacher doesn't seem to have any particular strategy in terms of EMI. She simply lays stress on English, as it is the medium of instruction. She finds it very important for teachers to mainly focus on students' comprehensibility and comprehension. Therefore, she acts accordingly.

\section{Teacher B}

Teacher B teaches Social Studies and English at a government EMI school in Province No 2, Nepal. He has been teaching the subjects in Classes 9 and 10 for five years. His classes are also heterogeneous with multicultural and multilingual identities and practice. He has attended several international conferences organized by Nepal English Language Teachers' Association (NELTA) with the presentation of one or two papers. He has also attended several governmentfunded teacher training programmes as a trainee, as well as a trainer.

Teaching techniques. The teacher's teaching techniques are also traditional. He has managed or prepared notes of chapters that he found challenging. While teaching Social Studies in the classroom, he reads (between) the lines. He explains the topics and communicates with students in English. He teaches stories and essays in English by summarizing in simpler language. He switches to Hindi, Nepali and Bhojpuri frequently. According to him, he has to do so, as students want to have much clearer concept in the languages they can feel comfortable. He uses some teaching videos, as well as motivational ones in English in the classrooms from time to time. He also motivates and urges students to speak in English in the classroom. He dictates answers to important questions to the students, and 
asks them to read them repeatedly to memorization. What he finds the most prominent is to make students, school administrators and parents satisfied no matter what techniques he is supposed to employ.

Achievements. The teacher can satisfy students with multilingual interpretations with the dictated answers. His code switching is mainly to convey important ideas from comprehension and examination view-points. Students, in his classroom, answer and communicate with him in English, although they switch to other languages whenever they find it hard to explain in English. He urges students to speak in English to control classes and motivates them to study by showing some teaching and motivational videos. Most of the students can pass exams in the subjects he teaches.

Challenges. Although he teaches English at the secondary level at EMI school, he finds it very hard to make students to have frequent interactions in English. He explains it as a socio-cultural impact, and students' tendency to opt for an easier aspect if at hand. Although multilingual pedagogy is student-friendly, the students are hardly seen benefiting the opportunity to learn better English.

Strategies. Generally, he uses English and Nepali, so that students can understand better. However, he encourages and forces students to prioritize English as they are in EMI classes. He allows limited multilingual practice in classroom pedagogy asking students to restate in English.

\section{Teacher C}

Teacher $\mathrm{C}$ teaches only English at the higher secondary level at a private EMI school in Province No 3, Nepal. He is an MA and MPhil in English, however he prefers teaching grammar and literature. He has attended few training programmes and has hardly attended any international conferences. He has been teaching English for around 20 years. Almost all the students in his classes have EMI education background from the beginning with high Grade Point Average (GPA) at Secondary Education Examination (SEE) from National Education Board (NEB), Nepal. Most of the students have Nepali and Newari as their first language although the number of students from ethnic groups like Gurung, Tamang, Sherpa, etc. is also significant. They are hardly heard using their ethnic languages in the school premises. Most of them use more Nepali than English while communicating with each other. They speak or initiate with English while communicating with teachers. They often use English while communicating with the teachers of English. 
Teaching techniques. The teacher uses both English and Nepali in the classroom. He mostly teaches and explains in English. From time to time he switches to Nepali to stress some important points and whenever he feels students are in confusion. He allows students to use Nepali in the classroom while sharing important points and ideas with each other; however, he urges them to use English at first. He follows what school administration has imposed as mandatory rules in terms of selecting the llanguage.

Achievements. Urging students strongly to use English if they have to communicate with the teacher develop their habit of commnicating in English more efficiently. Although students are already able to communicate in English, they subconsciously prefer Nepali to English even when they are at school. Therefore, their having to use English mandatorily while communcating with teachers, especially with the teachers of English, makes them feel it quite natural to start a conversation or interaction in English.They do not use Nepali until they feel they must speak out what exactly they want to convey and they want teachers to see. Students' limited freedom to use their first language in their communication can make them feel they can get privileged to use Nepali in some crucial cases. It makes them psychologically comfortable to take their learning practically rather than being imposed.

Challenges. Even though most of the students are very good at speaking in English, around forty per cent of them have problems with written English. On several occasions they are unable to understand what exactly the teacher has conveyed. They seem to be too prompt to pick up the sense or to be less able to comprehend than speak. Moreover, they seem to be quite indifferent to bettering their grammar, simply stressing how to communicate.

Strategies. He encourages and urges students to use English much more frequently to get to the depth of exact sense they need to get or convey. He finds it hazardous to let students to express themselves in Nepali as it prevents them from having to get the exactness of the message they have to grasp or convey, using English repeatedly.

\section{Discussion}

The data collected from the three teachers based on their experiences of teaching at English medium schools were observed and analysed from three perspectives: parents and school administration's understandings of EMI, teachers and students' skills and strengths, and monolingual instruction in multilingual classes. 


\section{Parents and School Administrators' Understandings on EMI}

Parents and public school administrators hold different views on EMI at schools. Parents' perception, in this regard, is all about the successful career their children will have because of EMI. They have observed that the students from private English medium schools are appreciably different from those from government schools, especially their being frank to speak, and moreover in English. The parents believe that students' being able to speak English is the index of their quality education. They believe that the system is sure to equip students with their English efficiency, which adds personality and quality to their studies. As a result, they will have a successful career like doctors and engineers. No doubt, students' being good at English opens the doors to many more opportunities they will be able to adopt and adjust themselves in the international level education system. Their experiences at the level add additional values to their confidence and personality but EMI itself is not the sole reason for the achievements students will make as expected by parents. Ojha (2018) clearly mentions that the quality students gain is based on the quality teachers can provide in their teaching support. And, Sah (2018) also agrees to the English skills teachers need to have for successful practice of EMI at schools.

On the other hand, school administrators of public schools, especially the Head teachers, have their own reasons for EMI at schools. The prime reason is the dwindling number of students at the public schools without EMI because of parents and students' attraction towards education in the English medium. Parents doubt the quality education at Nepali medium public schools and students have inferior complexity when they are supposed to study at Nepali medium public schools. It gets justified by what Sah (2018, pp. 115-116) presents as a student's perception in this regard:

It [English] is an international language and is popular among everyone in the world. If we know English, noone can dominate us. Our friends and neighbors who go to English-medium private schools often dominate us.We feel inferior before them if we don't know English. So, if we learn English, we don't have to feel ashamed infront of them. We like English-medium [better] than Nepali.

However, it is crucial to measure and maintain the strength of available man power at public school, or to justify the preparedness of school with required man power. 


\section{English Skills of Teachers and Students}

It is good to have education in English medium as long as it is feasible and beneficial. However, mere imposition of EMI system on public schools without feasibility inspection or preparation is more counter-productive. Two of the three teachers sharing their experiences of teaching at private and public EMI schools hint the required ability the teachers are supposed to have for smooth EMI conduction at schools. At many more private English medium schools, most of the teachers lack English proficiency to deliver their teaching in English. They heavily depend on memorization or translation in Nepali or other local language. The problems in government EMI schools are more complicated. On the other hand, students' English skills also play a vital role in purposeful EMI at schools. Public schools have introduced EMI not because they are well prepared with efficient employees but because they have to survive with a good number of students. In course of collecting students, it is very tough to filter the students who may not the minimum requirements of English skills. Even though teachers may be qualified and competent enough to conduct classes in English if students are quite hopeless at English, there will be no way of teaching other than codemixing, code switching and memorization, unable to uphold the spirit of a EMI. The most striking point is that even teachers who are used to delivering excellent teaching in Nepali stumble in English. Sah (2018, p. 116) highlights the existing bitter realities addressing the teachers' helplessness like this:

The teachers who were trained in Nepali in their teacher preparation were faced with tremendous challenges to deliver lessons in English. The head teacher was aware of this problem as he shared: "Teachers don't have as much English proficiency as required for EMI, including myself". They are not able to transfer everything they know in English medium.

\section{Monolingual Instruction in Multilingual Classes}

As it is crystal clear that parents believe EMI at school as a matter of quality education. The quality parents wish for their children is quite complicated. On the one hand, they get impressed by the way children at renowned private English medium schools speak English, i.e. fluent speech in English means quality education to them. On the other hand, they want their children to be successful like doctors and engineers, quality content of knowledge, which cannot be addressed by the medium of instruction. EMI binds teachers and students to monolingual pedagogy that hinders students and teachers' natural exposure to content knowledge. Considering the cognitive development of students, 
multilingual awareness is growing worldwide making space in classroom pedagogy. Practice of multilingualism in the classes of teachers $A$ and $B$ reflects students and teachers concern about the content knowledge much more than the medium of instruction or communication. Even in the classroom of teacher C, students find it quite comfortable to interact in Nepali, a language other than English. All those incidents and practices in EMI schools reflect how teachers have to maintain balance between what to teach for students to grasp and how to teach, i.e. in which medium.

\section{Conclusion}

The rise of English as a global lanaguage results in the rise of aspirations and ambitions of all the stakeholders. Nepalese academia obersrves the damand of English soaring up with the growing implementation of EMI attached to hopes for academic and economic gains on the national and international platform (Bista, 2011 \& Khati, 2016). The products of renowned private EMI schools with good infrastructures and dedicated professionals have left deep impressions of EMI on students and parents in general. Hence studying at or sending students to EMI schools is a growing trend guided by the deeply-rooted discourse among parents that $\mathrm{EMI}$ is the basis of quality education and succesful career. A great number of private English medium schools, once discoursed as mushrooming educational business, are still fascinating enough for parents to send their children to EMI school, so that children can have fluent English with quality education. It creates tensions among public schools that have begun to adopt EMI policy and practice without the preparedness of teaching professionals, creating anothe tension among teachers who have to give classes in English without being trained in Englsh in their teacher education. However, in many more private schools in Nepal, EMI seems to be not only a slogan to unfairly convince parents for quality they expect but also a burdensome imposition to many more teachers who have had to be used to rote teaching learning. That is why Sah and Li (2018) concluded in their study that EMI within the framework of Nepali instruction seemed to aid neither content learning nor English acquisition in the lack of purposeful preparation and planning. Teachers and students at govenment and private schools seem to be dependent on Nepali, a broadly practised and psychologically believed lanaguage, as they switich to Nepali in 'so-called' EMI classes for exact comprehension of content matters. Hence, the way EMI is in practice at public schools, as well as many more private schools except some well-established ones supported by qualified professionals, is the reflection of poor preparation for the system. The matter of greatest concern is that such a practice may set-up a trend with the shifted, or rather corrupt, meaning and practice of EMI, and the 
genuine goals defined by EMI may be too complicated to achieve. Nevertheless, making use of code switching and code mixing as an attempt of teachers and students for explanation and comprehension of content matters is a feasible way to make EMI survive in some way in the context of multilingual classes. There need to be enough researches for effective EMI practice in Nepal. In addition, seeking how to utilize the multilingual characteristics of Nepalese classrooms may add a new dimension to EMI pedagogy.

\section{References}

Aryal, M. (2013, July 9). Nepal scores low on quality education. Global Issue. [blogpost]. Retrieved on 8-1-2019 from http://www.globalissues.org/ news/2013/07/09/17013.

Byun, K., Chu, H., Kim, M. Park, I. Kim, S., \& Jung, J. (2011). English-medium teaching in Korean higher education: Policy debates and reality. Higher Education, 62, 431449.

Cosgun, G. \& Hasirci, B. (2017). The impact of English medium instruction (EMI) on students' language abilities. International Journal of Curriculum and Instruction, 9, (2), 11-20. Retrieved from http://ijci.wcci-international.org/index.php/IJCl/ article/view/73.

Dearden, J. (2014). English as a medium of instruction- a growing global phenomenon. British Council. Retrieved from: https://www.britishcouncil.org/sites/default/ files/e484_emi_-_cover_option_3_final_web.pdf.

Ghimire, L. (2011). Ideologies in the educational language policies of Nepal. Nepalese Linguistics, 26, 36-44.

Hu, G. (2009). The craze for English-medium education in China: driving forces and looming consequences. English Today, 25(4), 47-54. Doi:10.1017/\$0266078409990472

Ibrahim, H. A., Anka, S. M., \& Yabo, N. U. (2017). English as a medium of instruction: Challenges to Nigerian primary schools. Journal of Simon Fraser University Library, 5 (2), 63-72. Retrieved from https://journals.sfu.ca/vict/index.php/vict/article/ viewFile/247/124.

Montgomery, S. (2004). Of towers, walls, and fields: Perspectives on language in science. Science, 303(5662), 1333-1335. Retrieved from: https://www.ncbi.nlm.nih.gov/ pubmed/14988554.

Naun, D. (2003). The impact of English as a global language on educational politicies and practices in the Asia-pacific region. TESOL Quarterly, 37(4), 589-613. Retrieved from http://www.nzdl.org/gsdl/collect/literatu/index/assoc/HASH01fc.dir/doc. pdf.

Ojha, L. P. (2018). Shifting the medium of instruction to English in community schools: 
Policies, practices and challenges in Nepal. In David Hayes (Eds.), English Language Teaching in Nepal: Research, Reflection and Practice (187-200). Kathmandu: British Council.

Phyak, P. B. (2011). Beyond the facade of language planning for Nepalese primary education: Monolingual hangover, elitism and displacement of local languages. Current Issues in Language Planning, 12(2), 265-287.

Sah, P. K. \& Li, G. (2018). English medium instruction (EMI) as linguistic capital in Nepal: Promises and Realities. International Multilingual Research Journal, 12(2),109123. DOI: $10.1080 / 19313152.2017 .1401448$.

Sah, P.K. (2015, August). English medium instruction (EMI) in Nepalese education: Potential or problem? [Blog article]. ELT CHOUTARI. Retrieved from http:// eltchoutari.com/2015/08/english-medium-instruction-emi-in-nepaleseeducationpotential-or-problem.

Tobin, L. (2011,February 21). Half of living languages face extinction. The Guardian. Retrieved from http://www.guardian.co.uk/education/2011/feb/21/endangeredlanguages-research-project. 